\title{
Verbal autopsy-based cause-specific mortality trends in rural KwaZulu-Natal, South Africa, 2000-2009
}

\author{
Abraham J Herbst ${ }^{1 *}$, Tshepiso Mafojane ${ }^{1}$ and Marie-Louise Newell ${ }^{1,2}$
}

\begin{abstract}
Background: The advent of the HIV pandemic and the more recent prevention and therapeutic interventions have resulted in extensive and rapid changes in cause-specific mortality rates in sub-Saharan Africa, and there is demand for timely and accurate cause-specific mortality data to steer public health responses and to evaluate the outcome of interventions. The objective of this study is to describe cause-specific mortality trends based on verbal autopsies conducted on all deaths in a rural population in KwaZulu-Natal, South Africa, over a 10-year period (2000-2009).

Methods: The study used population-based mortality data collected by a demographic surveillance system on all resident and nonresident members of 12,000 households. Cause of death was determined by verbal autopsy based on the standard INDEPTH/WHO verbal autopsy questionnaire. Cause of death was assigned by physician review and the Bayesian-based InterVA program.
\end{abstract}

Results: There were 11,281 deaths over 784,274 person-years of observation of 125,658 individuals between Jan. 1, 2000 and Dec. 31, 2009. The cause-specific mortality fractions (CSMF) for the population as a whole were: HIVrelated (including tuberculosis), 50\%; other communicable diseases, 6\%; noncommunicable lifestyle-related conditions, 15\%; other noncommunicable diseases, 2\%; maternal, perinatal, nutritional, and congenital causes, 1\%; injury, 8\%; indeterminate causes, 18\%. Over the course of the 10 years of observation, the CSMF of HIV-related causes declined from a high of 56\% in 2002 to a low of 39\% in 2009 with the largest decline starting in 2004 following the introduction of an antiretroviral treatment program into the population. The all-cause agestandardized mortality rate (SMR) declined over the same period from a high of 174 (95\% confidence interval [CI]: $165,183)$ deaths per 10,000 person-years observed (PYO) in 2003 to a low of $116(95 \%$ Cl: 109, 123) in 2009. The decline in the SMR is predominantly due to a decline in the HIV-related SMR, which declined in the same period from 96 (95\% Cl: 89, 102) to 45 (95\% Cl: 40, 49) deaths per 10,000 PYO.

There was substantial agreement $(79 \% \mathrm{kappa}=0.68(95 \% \mathrm{Cl}: 0.67,0.69))$ between physician coding and InterVA coding at the burden of disease group level.

Conclusions: Verbal autopsy based methods enabled the timely measurement of changing trends in cause-specific mortality to provide policymakers with the much-needed information to allocate resources to appropriate health interventions.

\footnotetext{
* Correspondence: kherbst@africacentre.ac.za

${ }^{1}$ Africa Centre for Health and Population Studies, University of KwaZulu-

Natal, Somkhele, South Africa

Full list of author information is available at the end of the article
} 


\section{Background}

The advent of the HIV pandemic and the more recent prevention and therapeutic interventions have resulted in extensive and rapid changes in cause-specific mortality rates in sub-Saharan Africa during the last two decades [1-3]. South Africa, in particular, with a severe HIV epidemic, experienced a steep rise in adult mortality during the 1990s and the early part of this decade $[4,5]$ and is one of few countries where child mortality increased from the 1990 baseline [6]. In the past few years, evidence is emerging from South Africa $[7,8]$ and elsewhere in sub-Saharan Africa [9-12] that HIV-related mortality is declining following the introduction of prevention and treatment programs. In South Africa, these changes have occurred against the backdrop of a steadily increasing noncommunicable disease burden [13] and high trauma-related mortality [14]. With limited reliable data as to whether HIVrelated health care is flourishing to the detriment of nonHIV care, there is demand for timely and accurate causespecific mortality data to steer public health responses and to evaluate the outcome of interventions [15].

Due to the lack of death registration systems in the majority of the world's poorest settings, verbal autopsybased mortality surveillance has become one of the methods of choice to obtain the much needed cause-specific mortality data [15]. In particular, health and demographic surveillance sites have a role to play in this context to provide timely and accurate data [16]. Although South Africa has a functioning death registration system, the quality of cause of death data has been questioned $[17,18]$ and data from demographic surveillance studies using verbal autopsies have contributed to determining cause-specific mortality rates [19-21] in the country.

Verbal autopsy (VA) methods have traditionally depended on physician assessment of the verbal autopsy interview data to determine a cause of death [22], but the efficiency, reliability, and repeatability of this approach have recently been questioned [22,23]. Alternative methods to determine the cause of death on the basis of a verbal autopsy interview have been developed $[22,24]$, such as the InterVA (http://www.interva.net) system, which applies Bayes' theorem to derive probable causes of death from VA data [25].

Using data from a well-established longitudinal demographic surveillance, this study describes cause-specific mortality trends based on verbal autopsies conducted on all deaths in a rural population in KwaZulu-Natal, South Africa, over a 10-year period (2000-2009).

\section{Methods}

\section{Study area and population}

The Africa Centre for Health and Population Studies hosts a demographic surveillance program in the district of Umkhanyakude in the province of KwaZulu-Natal, South Africa [26]. Although it is largely rural, the demographic surveillance area (DSA), consisting of 435 square kilometers, also includes a township and periurban informal settlements. The population is characterized by high HIV prevalence [27] and incidence [28], but following the introduction of prevention of motherto-child transmission of HIV infection (in 2001) and antiretroviral treatment and care (in 2004) programs, child [8] and adult [7] all-cause mortality have started to decline. The study population has comparatively high levels of cardiovascular risk factors [29] and high trauma-related mortality [30].

\section{Mortality data}

The approximately 12,000 households in the DSA were visited thrice annually by fieldwork teams and all deaths were notified. Upon death notification, a trained nurse conducted an interview with the closest caregiver (parent or grandparent, 26\%; spouse, child, or grandchild, $25 \%$; other relative, $20 \%$; sibling, $14 \%$ ) of the deceased on average six months after the death. The nurses recorded a narrative of the circumstances leading up to the death and completed a questionnaire based on the standard INDEPTH/WHO verbal autopsy questionnaire $[31,32]$. Interviews were conducted in the local language and transcribed by the interviewer, after verbal consent. There were 228 (2\%) refusals and $102(0.9 \%)$ cases where a suitable interviewee could not be identified. A total of 13 nurses acted as interviewers over the course of the study; $80 \%$ of the interviews were conducted by six of these nurses. The majority of the nurses were graduate professional nurses; the remainder had twoyear nursing diplomas. All were previously employed with local health services and received training in administering the verbal autopsy questionnaire.

Two methods were used to determine cause of death for each case: physician coding and an automated method using the InterVA v3 probabilistic verbal autopsy interpretation model. In the physician-coded method, two clinicians independently assigned cause of death on the basis of the information collected during the verbal autopsy and their clinical judgement. If consensus could not be reached between the physicians, the VA interview was refused, or no suitable interviewee could be found, the cause of death was recorded as "undetermined." A third clinician reviewed all cases and codified the causes of death using the International Classification of Diseases, $10^{\text {th }}$ revision (ICD-10)[33]. The ICD-10 codes were mapped into global burden of disease groups (Table 1) using the crosswalk in Lopez [34]. A total of 27 physicians were involved over the course of the study period (2000 to 2009) in assigning 
Table 1 Burden of disease groups

\begin{tabular}{|c|c|c|}
\hline Cause category & Abbreviation & Burden of disease codes \\
\hline HIV-related causes & HIV-related & U003, U009 \\
\hline Other communicable diseases & Other CD & 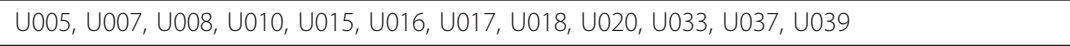 \\
\hline $\begin{array}{l}\text { Maternal, perinatal, nutritional, and } \\
\text { congenital causes }\end{array}$ & MPNC & U042, U043, U044, U045, U047, U048, U050, U051, U052, U054, U131, U136, U139, U140, U142 \\
\hline $\begin{array}{l}\text { Noncommunicable lifestyle-related } \\
\text { conditions }\end{array}$ & Lifestyle & $\begin{array}{l}\text { U079, U105, U106, U107, U108, U109, U110, U112, U113, U114, U116, U117, U119, U120, U121, } \\
\text { U122, U123 }\end{array}$ \\
\hline $\begin{array}{l}\text { Other noncommunicable } \\
\text { conditions }\end{array}$ & Other NCD & 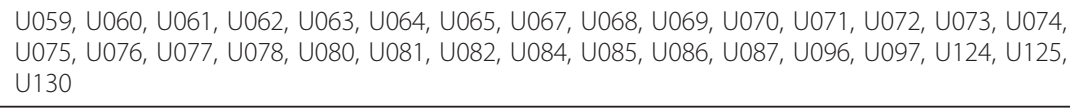 \\
\hline Injuries & Injuries & U148, U150, U151, U152, U153, U154, U155, U157, U158 \\
\hline Indeterminate causes & Indeterminate & U000, Z900, Z993, Z994, Z997, Z998, Z999 \\
\hline
\end{tabular}

diagnoses, however, eight physicians were responsible for $79 \%$ of the recorded diagnoses. Complete cause of death coding for the physician-coded diagnoses was available for deaths between 2000 and the end of 2008 .

The InterVA model is based on Bayesian calculations of probabilities that a particular death was due to particular causes, given a set of symptoms and circumstances associated with the death [25]. The verbal autopsy questionnaire data were converted into the 106 input indicators required by the InterVA probabilistic model using an SQL script. Cause of death categories were obtained by running InterVA in batch mode on the input indicators with malaria prevalence set to "low" and HIV prevalence set to "high." The 35 possible InterVA cause categories were mapped to the corresponding burdenof-disease codes to have cause categories comparable to the physician-coded diagnoses. InterVA produced up to three possible causes of death per case with a likelihood value between 0 and 1 for each cause. In cases where the likelihood values did not sum to 1 for a particular case, the difference between the sum of the likelihood values for the identified causes and 1 were allocated to the "indeterminate" cause. As recommended by the developers of InterVA, all identified causes were considered proportionate to their likelihood values in the rate calculations.

\section{Data analysis}

Deaths and person-years of observation were aggregated annually for the period from Jan. 1, 2000, to Dec. 31, 2009 , for all individuals in the study population.

Individuals contributed to the person-years denominator from Jan. 1, 2000, or from any later date of birth or in-migration, until Dec. 31, 2009, and they ceased to contribute to the denominator at death, termination of household membership, household out-migration, or the last surveillance visit in which household membership was confirmed. Thus, individuals who were previous homestead residents continued to be followed when they became nonresidents for as long as they remained a member of (retained links with) the household under surveillance. Out-migrants continued to be followed as nonresident household members in $83 \%$ of emigrations over the duration of the study.

We stratified mortality analysis by five age groups (under 5, 5-14, 15-49, 50-64, and over 65 years). The age-group boundaries were chosen to separate groups of public health importance and different patterns of mortality. There were no major changes in age group composition over the course of the study, and agestandardized mortality rates did not differ significantly on a year-to-year basis, therefore crude mortality rates are reported throughout. Under-5 mortality rates were expressed as deaths per person-years observed, rather than the customary deaths per live births, for consistent comparison to the mortality rates in the other age groups. Exact Poisson confidence intervals were calculated for all-cause mortality rates and cause-specific mortality rates and fractions where those were based on the single-cause physician-coded causes [35]. Confidence intervals for cause-specific mortality rates and fractions in the case of the InterVA-coded causes were calculated with $\mathrm{R}$ [36] using bootstrapping. Cause-specific mortality rates and fractions were based on the InterVA-determined causes unless otherwise stated. The kappa analysis was done using STATA v11 [37].

Ethical approval for the Africa Centre Demographic Surveillance was provided by the University of KwaZulu-Natal Bio-Medical Research Ethics Committee.

\section{Results}

\section{Mortality}

There were 11,281 deaths over 784,274 person years of observation of 125,658 individuals between Jan. 1, 2000 and Dec. 31, 2009 (Table 2). All causes of death were coded using InterVA; the 10,267 deaths between Jan. 1, 2000 and Dec. 31, 2008, were physician-coded as well. All-cause age-standardized mortality (SMR) for the total 
Table 2 Person-years observed, number of deaths, and sum of InterVA likelihood values per cause of death by age group and year

\begin{tabular}{|c|c|c|c|c|c|c|c|c|c|}
\hline $0-4 \mathrm{yr}$ & PYO & Deaths & HIV-related & MPNC & Injuries & Lifestyle & Other NCD & Other CD & Indeterminate \\
\hline 2000 & 9,304 & 185 & 93.7 & 9.2 & 2.4 & 0.3 & - & 40.5 & 38.9 \\
\hline 2001 & 9,761 & 202 & 95.4 & 10.2 & 0.7 & 2.4 & - & 57.4 & 35.9 \\
\hline 2002 & 9,969 & 216 & 87.5 & 13.7 & 5.5 & - & - & 64.8 & 44.5 \\
\hline 2003 & 9,806 & 201 & 71.3 & 4.1 & 1.7 & 1.9 & - & 60.3 & 61.8 \\
\hline 2004 & 9,837 & 140 & 38.1 & 4.9 & 1.9 & - & - & 30.0 & 65.1 \\
\hline 2005 & 9,939 & 141 & 38.0 & 3.5 & 0.7 & - & - & 47.6 & 51.1 \\
\hline 2006 & 10,127 & 118 & 35.5 & 4.2 & 1.9 & 0.6 & 0.8 & 48.6 & 25.5 \\
\hline 2007 & 10,508 & 109 & 36.0 & 3.8 & 2.3 & 0.7 & - & 39.9 & 26.3 \\
\hline 2008 & 10,539 & 118 & 28.6 & 4.7 & 3.0 & 0.7 & - & 53.9 & 27.1 \\
\hline 2009 & 10,483 & 102 & 12.2 & 1.0 & 3.2 & 0.5 & - & 50.8 & 34.4 \\
\hline $5-14 \mathrm{yr}$ & PYO & Deaths & HIV-related & MPNC & Injuries & Lifestyle & Other NCD & Other CD & Indeterminate \\
\hline 2000 & 19,642 & 22 & 3.2 & - & 6.8 & 1.7 & 1.4 & 4.7 & 4.3 \\
\hline 2001 & 20,723 & 31 & 13.7 & - & 4.5 & 2.6 & 0.1 & 4.6 & 5.5 \\
\hline 2002 & 21,710 & 35 & 13.0 & - & 4.0 & 1.0 & 1.6 & 8.6 & 6.9 \\
\hline 2003 & 22,218 & 41 & 14.2 & - & 10.5 & 2.2 & 0.6 & 2.8 & 10.7 \\
\hline 2004 & 22,416 & 49 & 25.5 & - & 10.6 & 3.0 & - & 1.6 & 8.4 \\
\hline 2005 & 22,181 & 38 & 18.1 & - & 6.9 & 2.7 & - & 1.3 & 8.9 \\
\hline 2006 & 22,052 & 33 & 15.7 & - & 2.8 & 1.0 & 0.7 & 5.4 & 7.4 \\
\hline 2007 & 22,078 & 27 & 11.8 & - & 4.5 & 0.6 & - & 4.7 & 5.5 \\
\hline 2008 & 21,697 & 36 & 8.3 & - & 9.2 & 2.0 & 1.8 & 4.1 & 9.7 \\
\hline 2009 & 21,288 & 22 & 12.9 & - & 3.2 & 0.2 & - & 1.6 & 4.1 \\
\hline $15-49 \mathrm{yr}$ & PYO & Deaths & HIV-related & MPNC & Injuries & Lifestyle & Other NCD & Other CD & Indeterminate \\
\hline 2000 & 28,618 & 441 & 327.4 & 4.1 & 34.9 & 32.3 & 0.3 & 5.2 & 36.8 \\
\hline 2001 & 32,154 & 547 & 394.0 & 2.4 & 56.1 & 30.7 & 2.2 & 9.7 & 52.0 \\
\hline 2002 & 35,475 & 625 & 485.4 & 2.6 & 44.2 & 29.5 & 3.2 & 6.6 & 53.5 \\
\hline 2003 & 37,350 & 701 & 523.1 & 5.8 & 55.2 & 28.1 & 7.2 & 10.2 & 71.5 \\
\hline 2004 & 39,059 & 694 & 480.6 & 3.1 & 81.2 & 26.3 & 5.1 & 4.3 & 93.3 \\
\hline 2005 & 40,277 & 647 & 438.2 & 5.2 & 60.2 & 29.9 & 7.2 & 6.4 & 100.1 \\
\hline 2006 & 41,826 & 580 & 375.6 & 2.1 & 73.2 & 26.2 & 3.3 & 7.4 & 92.3 \\
\hline 2007 & 43,399 & 624 & 413.2 & 4.7 & 62.3 & 28.5 & 3.4 & 6.9 & 105.1 \\
\hline 2008 & 44,235 & 509 & 294.6 & 1.8 & 85.4 & 23.7 & 6.3 & 4.9 & 92.3 \\
\hline 2009 & 45,236 & 495 & 274.2 & 4.7 & 73.3 & 26.0 & 6.3 & 6.1 & 104.6 \\
\hline $50-64 \mathrm{yr}$ & PYO & Deaths & HIV-related & MPNC & Injuries & Lifestyle & Other NCD & Other CD & Indeterminate \\
\hline 2000 & 4,325 & 124 & 49.3 & - & 10.8 & 36.4 & 4.4 & 3.5 & 19.6 \\
\hline 2001 & 4,433 & 153 & 62.6 & - & 14.2 & 49.2 & 4.3 & 3.9 & 18.9 \\
\hline 2002 & 4,553 & 125 & 60.7 & - & 4.2 & 40.0 & 1.1 & 2.8 & 16.3 \\
\hline 2003 & 4,666 & 159 & 70.0 & - & 8.1 & 46.5 & 8.4 & 2.8 & 23.3 \\
\hline 2004 & 4,735 & 136 & 64.1 & - & 3.0 & 30.5 & 6.5 & 3.4 & 28.5 \\
\hline 2005 & 4,714 & 167 & 84.8 & - & 5.9 & 35.6 & 8.2 & 2.7 & 29.8 \\
\hline 2006 & 4,715 & 164 & 60.7 & - & 7.8 & 43.1 & 6.6 & 4.7 & 41.2 \\
\hline 2007 & 4,836 & 169 & 74.2 & - & 5.0 & 41.6 & 3.3 & 2.9 & 41.9 \\
\hline 2008 & 4,990 & 155 & 55.7 & - & 7.0 & 45.5 & 9.6 & 3.7 & 33.5 \\
\hline 2009 & 5,152 & 174 & 62.1 & - & 6.8 & 46.7 & 10.8 & 4.2 & 43.5 \\
\hline
\end{tabular}


Table 2 Person-years observed, number of deaths, and sum of InterVA likelihood values per cause of death by age group and year (Continued)

\begin{tabular}{|c|c|c|c|c|c|c|c|c|c|}
\hline $65+y r$ & PYO & Deaths & HIV-related & MPNC & Injuries & Lifestyle & Other NCD & Other CD & Indeterminate \\
\hline 2000 & 3,059 & 139 & 28.4 & 1.6 & 2.8 & 64.0 & 4.3 & 8.0 & 29.9 \\
\hline 2001 & 3,134 & 196 & 24.8 & 1.9 & 3.6 & 98.3 & 7.7 & 13.4 & 46.3 \\
\hline 2002 & 3,170 & 226 & 34.8 & 2.8 & 8.9 & 103.8 & 14.2 & 7.9 & 53.5 \\
\hline 2003 & 3,187 & 216 & 31.7 & 1.6 & 5.2 & 102.2 & 12.1 & 12.2 & 51.0 \\
\hline 2004 & 3,268 & 202 & 33.2 & 2.5 & 10.1 & 92.8 & 5.8 & 9.1 & 48.5 \\
\hline 2005 & 3,396 & 198 & 36.0 & - & 6.1 & 74.2 & 15.9 & 8.0 & 57.8 \\
\hline 2006 & 3,494 & 197 & 30.2 & 1.8 & 8.7 & 77.1 & 13.2 & 7.1 & 59.0 \\
\hline 2007 & 3,526 & 229 & 42.6 & 0.7 & 8.8 & 100.6 & 10.1 & 3.8 & 62.4 \\
\hline 2008 & 3,539 & 212 & 25.3 & 0.4 & 9.8 & 104.7 & 6.0 & 5.7 & 60.1 \\
\hline 2009 & 3,474 & 211 & 28.0 & 1.1 & 5.9 & 100.6 & 10.4 & 3.3 & 61.7 \\
\hline
\end{tabular}

population changed from 139 (95\% CI: 130, 148) deaths per 10,000 person-years observed (PYO) in 2000 to a maximum of $174(95 \%$ CI: 165, 183) in 2003 and then declined to 116 (95\% CI: 109, 123) in 2009 (Figure 1). HIV-related causes were responsible for $50 \%$ of the deaths over the period from 2000 to 2009, followed by indeterminate causes at $18 \%$ and lifestyle-related noncommunicable diseases at $15 \%$ of all deaths. HIV-related causes were responsible for a maximum $56 \%$ of deaths in 2002 , declining to a minimum of $39 \%$ of deaths in 2009. Indeterminate causes were responsible for a minimum of $14 \%$ of deaths during 2000 , rising to a maximum of $25 \%$ in 2009.

The largest proportion (52\%) of deaths occurred in the 15-49 age group followed by the 65 and older age group at $18 \%$. The under- 5 age group contributed $20 \%$ of the deaths in 2000, but this declined to between $9 \%$ and $11 \%$ from 2007 to 2009 . Overall, $82 \%$ of all deaths

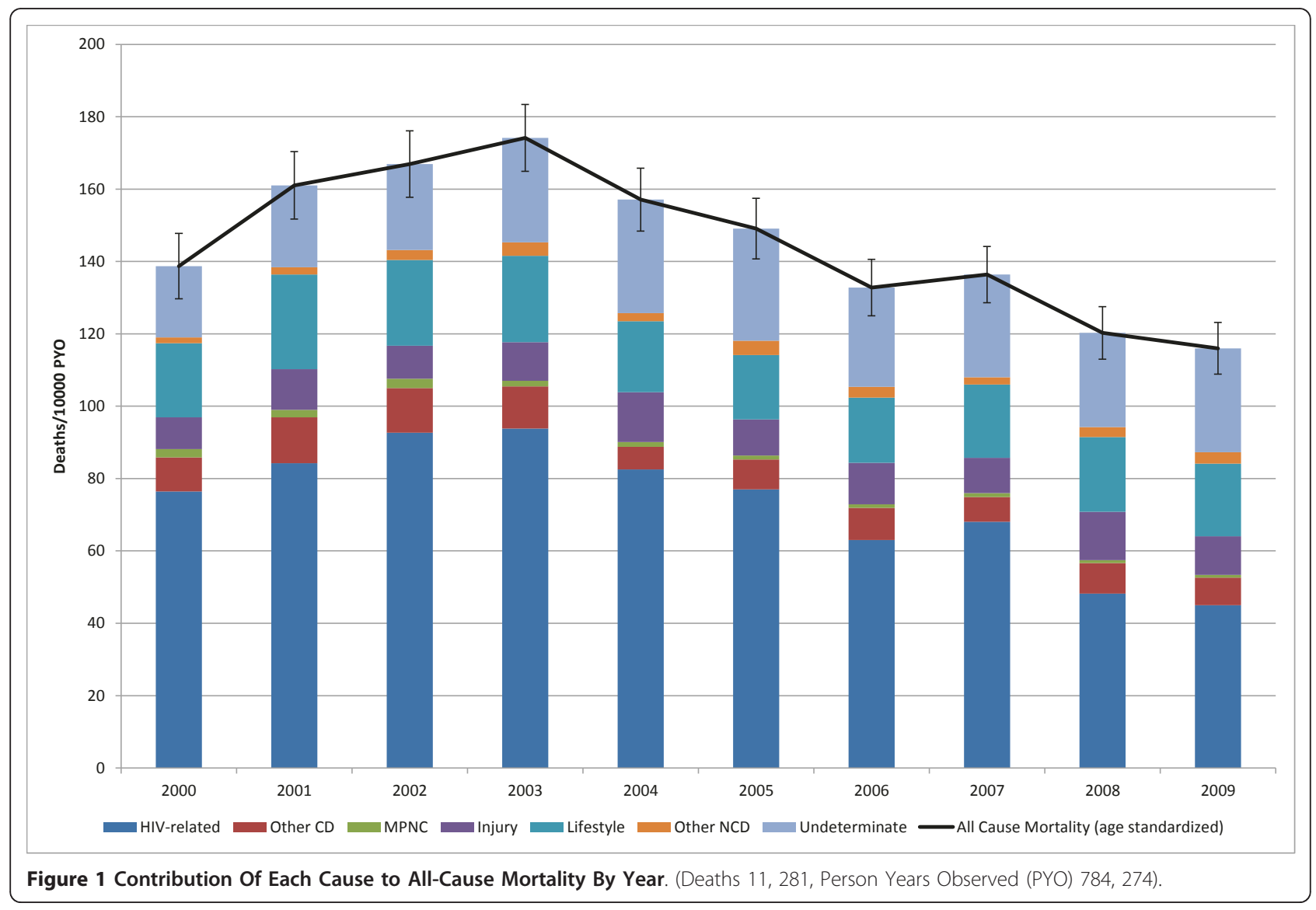


occurred before the age of 65 years, declining from a high of $85 \%$ in 2000 to $79 \%$ in 2009 (Figure 2).

The under-5 all-cause SMR peaked at 217 (95\% CI: 189, 245) deaths per 10,000 PYO in 2002 and then declined rapidly to 103 (95\% CI: 83,103) in 2009 (Figure 3). This is greater than a twofold decline in mortality. HIV-related mortality (Table 3 ) in this age group had a high in 2000 of 101 deaths per 10,000 PYO (95\% CI: 86,115), plateaued at around 37 deaths per 10,000 PYO between 2004 and 2007, and then declined further to a low of 12 (95\% CI: 6, 17) in 2009. Other communicable disease SMR varied between 31 (95\%: CI 22, 38) in 2004 and 65 (95\% CI: 54, 76) deaths per 10,000 PYO in 2002. Mortality due to indeterminate causes was high in this age group varying around 41 deaths per 10,000 PYO and peaked around 60 deaths per 10,000 between 2003 and 2005. The cause-specific mortality fraction (CSMF) due to HIVrelated causes declined from 51\% (95\% CI: 44, 58) in 2000 to $12 \%$ (95\% CI: 6, 17) in 2009. As a result of the overall decline in the mortality rate in this age group, the CSMF for other communicable diseases increased from $22 \%(95 \%$ CI: 17,27$)$ in 2000 to $50 \%$ (95\% CI: 42 , 57 in 2009. The all-cause SMR for the 5-14 age group peaked at 22 (95\% CI: 16, 28) deaths per 10,000 PYO in 2004 and then declined to 10 (95\% CI: 6, 15) in 2009 (Figure 4).

The all-cause SMR for the 15-49 age group peaked at 190 (95\% CI: 176, 203) deaths per 10,000 PYO in 2003 and then declined to 109 (95\% CI: 100, 119) in 2009 (Figure 5). HIV-related mortality peaked in 2003 at 140 (95\% CI: 135, 145) deaths per 10,000 PYO and then declined to 61 (95\% CI: 56, 65) in 2009 (Table 3). The CSMF for HIV-related causes declined from 74\% (95\% CI: 71, 78) in 2000 to $55 \%$ (95\% CI: 52, 59) in 2009. This decline in HIV-related CSMF appears to be at the expense of an increase in indeterminate CSMF, which increased over the same period from $8 \%(95 \%$ CI: 7,10$)$ to $21 \%$ (95\% CI: 19,24$)$.

There was no discernible trend in all-cause mortality in the 50-64 age group (Figure 6). HIV-related causes constituted the largest CSMF at $42 \%$ for the entire period, followed by lifestyle-related noncommunicable diseases at $27 \%$ and indeterminate causes at $19 \%$. There was no significant trend in HIV-related mortality and the highest mortality rates observed occurred in 2005 (180 (95\% CI: 156, 206)) and 2007 (154 (95\% CI: 129, 179)) after the introduction of an antiretroviral therapy

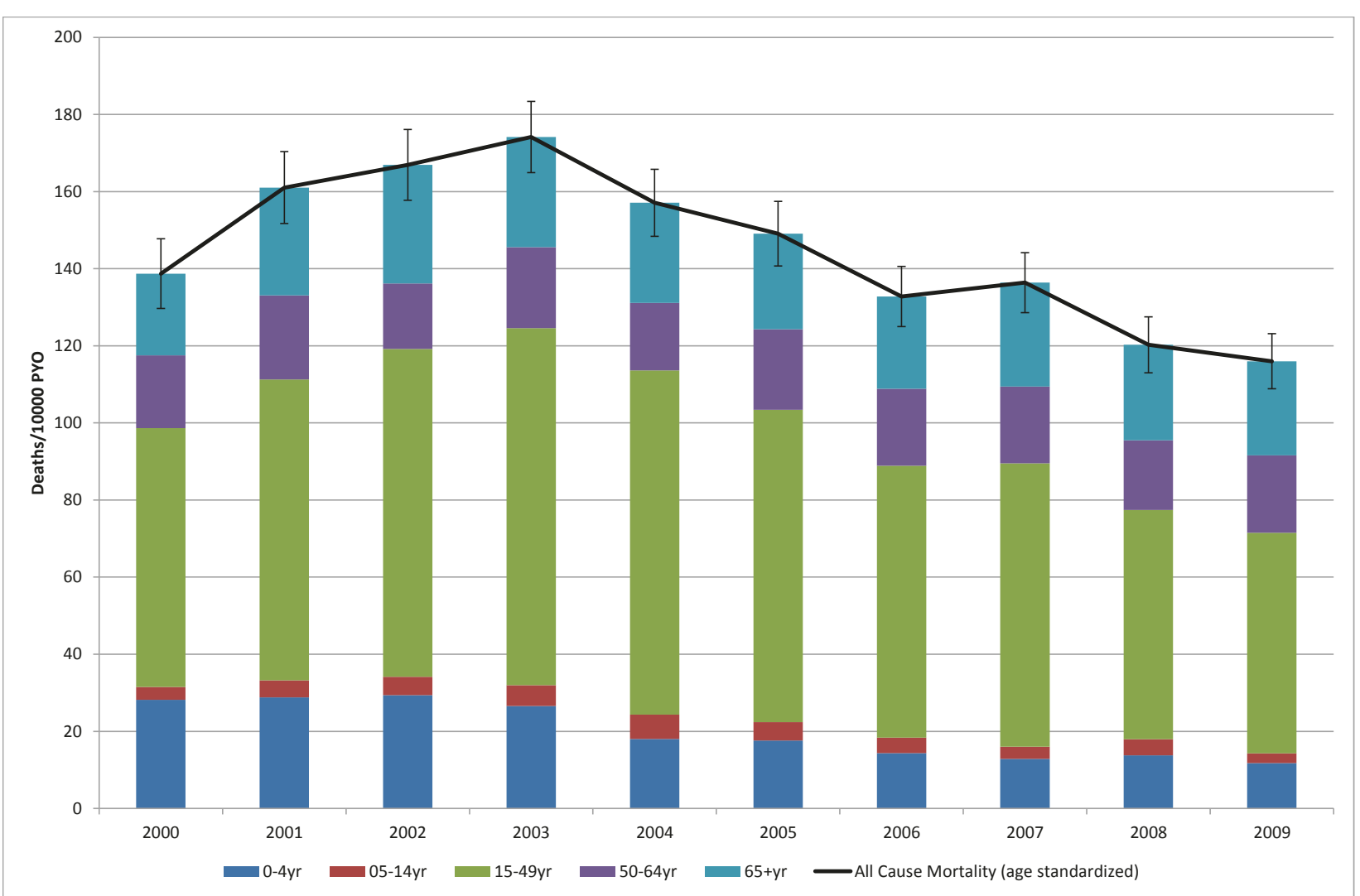

Figure 2 Contribution Of Each Age Group to All-Cause Mortality By Year. (Deaths 11, 281, Person Years Observed (PYO) 784, 274). 


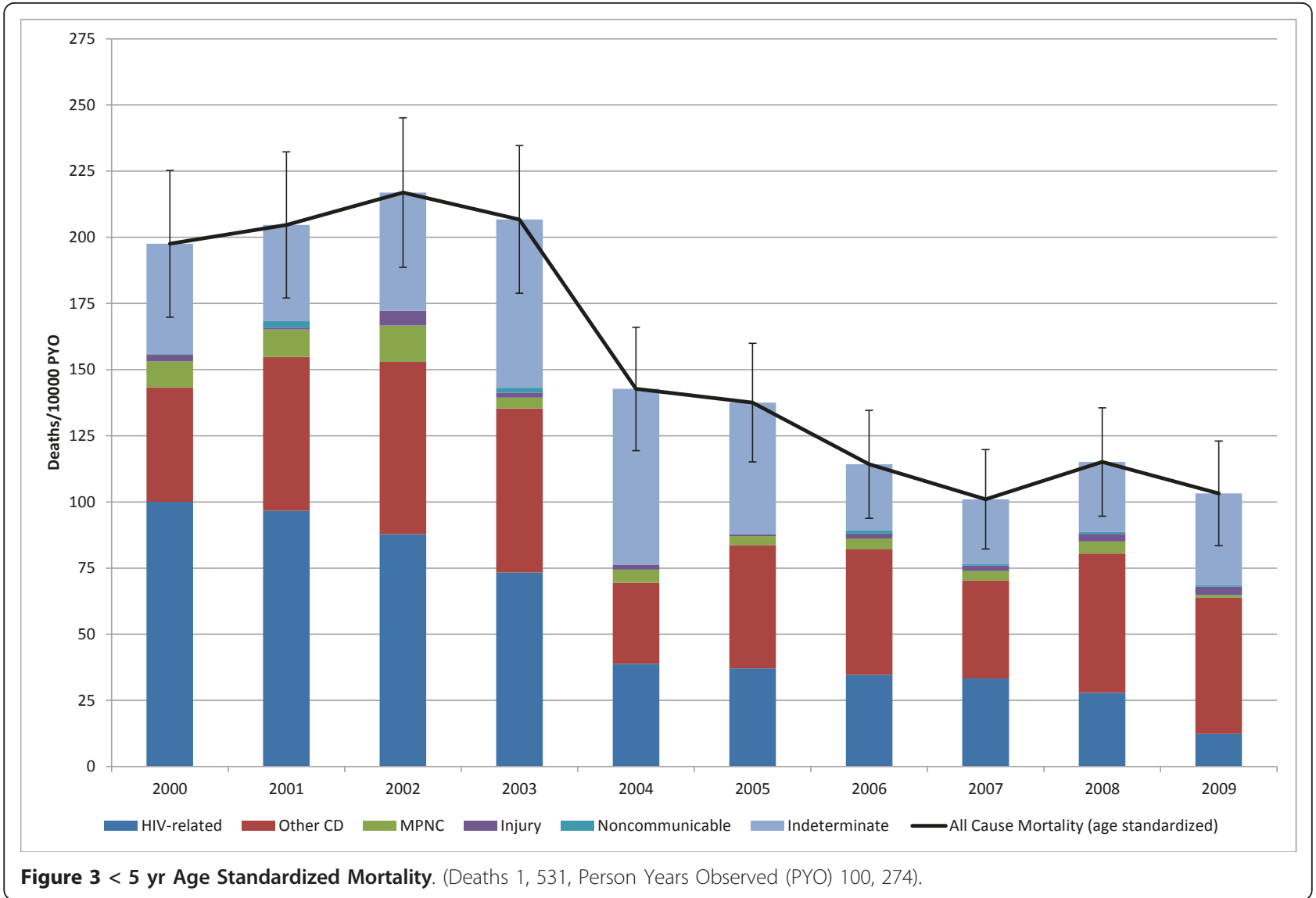

(ART) program in the area in 2004 (Table 3). Lifestylerelated noncommunicable mortality remained stable at around 88 deaths per 10,000 PYO.

Age-standardized mortality in the over-65 age group appeared to increase in the early part of the decade, rising from $453(95 \% \mathrm{CI}: 377,528)$ deaths per 10,000 in 2000 to a peak of 721 (95\% CI: 631,812) in 2002 and plateauing off to remain stable at around 611 deaths per 10,000 PYO (Figure 7). Noncommunicable diseases were responsible for the largest CSMF at 50\%, with lifestyle-related CSMF at $45 \%$. Indeterminate (26\%) and HIV-related (16\%) causes were also important.

\section{Comparison of physician with InterVA coding}

There was substantial agreement (79\% kappa $=0.68$ (95\% CI: $0.67,0.69)$ ) between physician coding and InterVA coding at the burden of disease group level. This agreement varied significantly among age groups (Table 4), with the lowest agreement in the under-5 age group (kappa $=0.44(95 \% \mathrm{CI}: 0.41,0.47))$ and the over65 age group (kappa $=0.50$ (95\% CI: 0.48, 0.52)), with the remaining age groups around the overall agreement level. There were no significant changes in agreement over time (Table 5).

\section{Discussion}

Cause-specific mortality trends in the under-5 age group and the 15-49 age group were dominated by trends in HIV-related mortality in response to the introduction of interventions such as preventing mother-to-child transmission of HIV (PMTCT) and ART [7,8]. There were no significant trends in other causes of mortality in these age groups. The CSMF for HIV-related causes for the under-5 age group (34\%) for the 2002-2005 period was higher than the value (26\%) reported by Byass [20] using InterVA (with the same set of input indicators as used by this study) for the same period in Agincourt, a demographic surveillance site in the Mpumalanga province of South Africa. In the case of the 15-49 age group, the HIV-related CSMF (72\%) in this study was also higher than the value (54\%) reported for the Agincourt site.

In the older age groups, HIV-related mortality remained important but showed no significant decline in the second half of the 2000-2009 period. 
Table 3 Cause-specific mortality rates by age group and year (per 10,000 person years observed)

\begin{tabular}{|c|c|c|c|c|c|}
\hline 2000 & $0-4$ yrs $(95 \% \mathrm{Cl})$ & $5-14$ yrs $(95 \% \mathrm{Cl})$ & $15-49$ yrs $(95 \% \mathrm{Cl})$ & $50-64$ yrs $(95 \% \mathrm{Cl})$ & $65+(95 \% \mathrm{Cl})$ \\
\hline HIV-related & $100.8(88.1-113.9)$ & $1.6(0.0-3.1)$ & $114.3(109.1-119.5)$ & $113.8(89.5-137.0)$ & $94.3(65.6-122.2)$ \\
\hline MPNC & $8.0(2.8-12.9)$ & - & $1.4(0.1-2.5)$ & - & $3.9(0.0-7.6)$ \\
\hline Injuries & $2.6(0.0-5.2)$ & $3.5(1.4-5.3)$ & $11.9(8.2-15.6)$ & $24.4(9.6-36.7)$ & $9.3(0.0-16.8)$ \\
\hline Lifestyle & $0.3(0.0-0.7)$ & $0.9(0.0-1.8)$ & $11.1(7.6-14.4)$ & $83.8(62.8-103.7)$ & $211.2(180.8-240.9)$ \\
\hline Other NCD & - & $0.7(0.0-1.4)$ & $0.2(0.0-0.5)$ & $11.1(2.6-18.0)$ & $18.1(3.8-29.5)$ \\
\hline Other CD & $45.0(35.4-54.5)$ & $2.4(0.3-4.2)$ & $1.6(0.3-2.7)$ & $5.5(0.0-11.5)$ & $22.0(11.0-32.8)$ \\
\hline Indeterminate & $42.1(33.7-49.1)$ & $2.2(1.2-3.0)$ & $13.4(11.1-15.6)$ & $48.2(35.9-59.0)$ & $95.6(78.0-113.6)$ \\
\hline 2001 & $0-4$ yrs $(95 \% \mathrm{Cl})$ & $5-14$ yrs $(95 \% \mathrm{Cl})$ & $15-49$ yrs $(95 \% \mathrm{Cl})$ & $50-64$ yrs $(95 \% \mathrm{Cl})$ & $65+(95 \% \mathrm{Cl})$ \\
\hline HIV-related & $97.7(84.6-110.8)$ & $6.6(4.4-9.1)$ & 122.9 (116.9-128.9) & $143.9(118.4-170.3)$ & 77.3 (50.9-102.3) \\
\hline MPNC & $10.0(4.1-15.2)$ & - & $0.4(0.0-0.9)$ & - & $6.1(0.0-12.2)$ \\
\hline Injuries & $0.7(0.0-1.4)$ & $2.2(0.4-3.7)$ & $17.2(12.5-21.5)$ & $31.9(15.7-47.4)$ & $10.3(0.0-19.3)$ \\
\hline Lifestyle & $2.5(0.1-4.5)$ & $1.5(0.0-2.7)$ & $9.9(6.5-12.6)$ & $111.4(87.4-135.0)$ & $324.3(283.6-365.0)$ \\
\hline Other NCD & - & $0.1(0.0-0.1)$ & $0.8(0.0-1.5)$ & $9.7(1.1-16.6)$ & $24.4(8.5-38.4)$ \\
\hline Other CD & $59.2(46.6-70.2)$ & $2.2(0.4-3.6)$ & $2.9(1.0-4.6)$ & $7.2(0.0-12.9)$ & $38.2(21.3-54.6)$ \\
\hline Indeterminate & $36.9(29.3-43.0)$ & $2.5(1.3-3.4)$ & $15.9(13.4-18.2)$ & $41.1(28.8-52.3)$ & $144.8(121.5-168.7)$ \\
\hline 2002 & $0-4$ yrs $(95 \% \mathrm{Cl})$ & $5-14$ yrs $(95 \% \mathrm{Cl})$ & $15-49$ yrs $(95 \% \mathrm{Cl})$ & $50-64$ yrs $(95 \% \mathrm{Cl})$ & $65+(95 \% \mathrm{Cl})$ \\
\hline HIV-related & $87.7(74.6-101.9)$ & $5.9(3.6-8.3)$ & $137.1(132.1-142.0)$ & $134.7(111.5-156.7)$ & $106.8(73.3-138.1)$ \\
\hline MPNC & $12.8(6.3-18.0)$ & - & $0.7(0.0-1.5)$ & - & $8.8(0.9-15.1)$ \\
\hline Injuries & $5.5(1.3-9.2)$ & $1.8(0.0-3.4)$ & $12.0(8.5-15.3)$ & $7.8(0.0-14.3)$ & $26.3(9.0-41.1)$ \\
\hline Lifestyle & - & $0.5(0.0-1.0)$ & $8.3(5.2-10.9)$ & $88.0(66.2-108.8)$ & $341.3(298.3-388.4)$ \\
\hline Other NCD & - & $0.7(0.0-1.5)$ & $0.9(0.0-1.7)$ & $2.4(0.0-4.9)$ & $46.9(27.1-65.0)$ \\
\hline Other CD & $65.6(54.5-76.9)$ & $4.0(1.9-5.8)$ & $1.8(0.4-3.0)$ & $5.5(0.0-10.6)$ & $22.7(7.9-35.8)$ \\
\hline Indeterminate & $45.0(37.4-51.7)$ & $3.2(1.7-4.4)$ & $15.3(13.0-17.6)$ & $36.2(23.9-46.9)$ & $160.3(132.6-187.5)$ \\
\hline 2003 & $0-4$ yrs $(95 \% \mathrm{Cl})$ & $5-14$ yrs $(95 \% \mathrm{Cl})$ & $15-49$ yrs $(95 \% \mathrm{Cl})$ & $50-64$ yrs $(95 \% \mathrm{Cl})$ & $65+(95 \% \mathrm{Cl})$ \\
\hline HIV-related & 72.7 (58.6-85.8) & $6.4(3.8-8.9)$ & $140.6(135.7-145.5)$ & $148.2(123.6-172.4)$ & $99.3(67.9-126.6)$ \\
\hline MPNC & $4.1(0.2-7.4)$ & - & $1.4(0.0-2.4)$ & - & $5.0(0.0-9.6)$ \\
\hline Injuries & $1.8(0.0-3.5)$ & $4.8(2.5-7.0)$ & $13.8(10.4-17.1)$ & $17.4(3.6-27.5)$ & $16.3(0.8-28.0)$ \\
\hline Lifestyle & $1.9(0.0-3.6)$ & $0.9(0.0-1.8)$ & $8.3(5.8-10.7)$ & $105.5(81.3-127.6)$ & $330.0(292.1-369.7)$ \\
\hline Other NCD & - & $0.3(0.0-0.6)$ & $1.9(0.6-3.1)$ & $18.4(7.4-28.2)$ & $39.6(18.2-58.8)$ \\
\hline Other CD & $61.6(49.5-73.0)$ & $1.3(0.1-2.3)$ & $2.7(1.2-4.1)$ & $5.0(0.0-9.6)$ & $31.3(16.0-44.9)$ \\
\hline Indeterminate & $62.9(51.6-73.0)$ & $4.9(2.9-6.6)$ & $18.9(16.6-21.1)$ & $46.3(36.7-55.4)$ & $156.2(131.2-181.2)$ \\
\hline 2004 & $0-4$ yrs $(95 \% \mathrm{Cl})$ & $5-14$ yrs $(95 \% \mathrm{Cl})$ & $15-49$ yrs $(95 \% \mathrm{Cl})$ & $50-64$ yrs $(95 \% \mathrm{Cl})$ & $65+(95 \% \mathrm{Cl})$ \\
\hline HIV-related & $38.7(27.8-49.1)$ & $11.4(8.7-14.3)$ & $123.8(118.5-129.4)$ & 130.7 (111.0-151.6) & $100.9(71.1-129.3)$ \\
\hline MPNC & $4.6(0.3-7.9)$ & - & $0.8(0.0-1.5)$ & - & $6.3(0.0-11.2)$ \\
\hline Injuries & $1.9(0.0-3.8)$ & $4.8(2.3-6.9)$ & $20.1(15.9-23.8)$ & $6.3(0.0-12.5)$ & $24.2(8.9-39.0)$ \\
\hline Lifestyle & - & $1.3(0.0-2.6)$ & $6.8(4.7-9.0)$ & $71.8(53.4-88.5)$ & $302.2(266.5-337.7)$ \\
\hline Other NCD & - & - & $1.3(0.3-2.2)$ & $13.8(4.3-21.7)$ & $18.4(4.7-30.4)$ \\
\hline Other CD & $30.5(23.0-38.9)$ & $0.7(0.0-1.4)$ & $1.0(0.2-1.7)$ & $5.2(0.0-9.4)$ & $19.8(8.0-29.9)$ \\
\hline Indeterminate & $66.6(55.9-76.7)$ & $3.6(1.8-5.2)$ & $23.9(20.5-27.2)$ & $59.6(45.6-72.5)$ & $146.1(122.4-169.3)$ \\
\hline 2005 & $0-4$ yrs $(95 \% \mathrm{Cl})$ & $5-14$ yrs $(95 \% \mathrm{Cl})$ & $15-49$ yrs $(95 \% \mathrm{Cl})$ & $50-64$ yrs $(95 \% \mathrm{Cl})$ & $65+(95 \% \mathrm{Cl})$ \\
\hline HIV-related & $38.3(29.5-46.9)$ & $8.2(5.3-10.9)$ & $108.9(103.7-114.6)$ & $179.4(154.0-201.9)$ & $104.3(74.4-131.6)$ \\
\hline MPNC & $3.6(0.2-6.3)$ & - & $1.2(0.3-2.0)$ & - & - \\
\hline Injuries & $0.7(0.0-1.4)$ & $3.1(1.1-5.0)$ & $14.5(11.0-17.5)$ & $12.5(2.0-21.0)$ & $17.8(3.9-30.0)$ \\
\hline Lifestyle & - & $1.2(0.0-2.4)$ & $7.9(5.3-10.2)$ & 78.7 (59.2-97.4) & $232.4(199.1-264.9)$ \\
\hline Other NCD & - & - & $1.8(0.8-2.7)$ & $17.6(5.7-27.3)$ & $52.3(30.9-73.2)$ \\
\hline Other CD & $47.9(38.7-57.3)$ & $0.6(0.0-1.2)$ & $1.5(0.5-2.4)$ & $4.0(0.0-7.4)$ & $17.8(4.6-27.8)$ \\
\hline Indeterminate & $51.4(43.0-58.6)$ & $4.0(2.1-5.9)$ & $24.8(21.2-27.9)$ & $62.1(46.8-76.9)$ & $158.3(130.4-183.0)$ \\
\hline
\end{tabular}


Table 3 Cause-specific mortality rates by age group and year (per 10,000 person years observed) (Continued)

\begin{tabular}{|c|c|c|c|c|c|}
\hline 2006 & $0-4$ yrs $(95 \% \mathrm{Cl})$ & $5-14$ yrs $(95 \% \mathrm{Cl})$ & $15-49$ yrs $(95 \% \mathrm{Cl})$ & $50-64$ yrs $(95 \% \mathrm{Cl})$ & $65+(95 \% \mathrm{Cl})$ \\
\hline HIV-related & $35.1(26.2-42.8)$ & $7.1(5.0-9.5)$ & $89.8(84.8-95.0)$ & $126.8(104.5-149.4)$ & $86.8(57.1-111.7)$ \\
\hline MPNC & $4.1(0.0-7.6)$ & - & $0.5(0.0-0.9)$ & - & $4.7(0.0-8.7)$ \\
\hline Injuries & $1.8(0.0-3.7)$ & $1.3(0.0-2.5)$ & $16.8(12.7-20.5)$ & $14.9(2.0-24.4)$ & $24.9(7.5-38.5)$ \\
\hline Lifestyle & $0.6(0.0-1.2)$ & $0.4(0.0-1.0)$ & $6.2(4.2-8.1)$ & $95.0(74.9-114.4)$ & $224.2(190.7-257.3)$ \\
\hline Other NCD & $0.8(0.0-1.6)$ & $0.3(0.0-0.7)$ & $0.8(0.0-1.4)$ & $13.9(4.2-21.4)$ & $39.4(21.0-57.1)$ \\
\hline Other CD & 47.9 (38.9-56.6) & $2.5(0.7-3.8)$ & $1.5(0.5-2.3)$ & $9.5(2.4-15.2)$ & $18.1(8.1-27.6)$ \\
\hline Indeterminate & $26.2(20.5-31.8)$ & $3.8(1.3-5.7)$ & $23.0(19.9-26.2)$ & $87.7(73.2-102.6)$ & $165.8(140.4-189.7)$ \\
\hline 2007 & $0-4$ yrs $(95 \% \mathrm{Cl})$ & $5-14$ yrs $(95 \% \mathrm{Cl})$ & $15-49$ yrs $(95 \% \mathrm{Cl})$ & $50-64$ yrs $(95 \% \mathrm{Cl})$ & $65+(95 \% \mathrm{Cl})$ \\
\hline HIV-related & $34.3(25.1-42.8)$ & $5.4(3.3-7.5)$ & $95.4(91.1-100.3)$ & $153.4(130.8-177.3)$ & $116.3(85.5-144.9)$ \\
\hline MPNC & $3.0(0.0-5.5)$ & - & $1.4(0.2-2.3)$ & - & $2.0(0.0-4.3)$ \\
\hline Injuries & $2.2(0.0-4.1)$ & $2.0(0.4-3.5)$ & $13.7(10.4-16.8)$ & $10.4(1.1-18.1)$ & $24.1(10.0-36.3)$ \\
\hline Lifestyle & $0.7(0.0-1.5)$ & $0.3(0.0-0.6)$ & $6.4(4.3-8.4)$ & 88.9 (66.7-109.4) & $296.1(261.9-328.5)$ \\
\hline Other NCD & - & - & $0.8(0.1-1.4)$ & $5.6(0.0-10.1)$ & $29.5(14.4-42.7)$ \\
\hline Other CD & $38.6(29.9-47.2)$ & $2.1(0.2-3.7)$ & $1.6(0.6-2.5)$ & $4.3(0.0-8.2)$ & $8.3(1.3-14.3)$ \\
\hline Indeterminate & $25.1(19.9-30.4)$ & $2.5(0.8-3.9)$ & $24.5(20.9-27.5)$ & $86.9(68.2-103.5)$ & $173.3(144.5-199.4)$ \\
\hline 2008 & $0-4$ yrs $(95 \% \mathrm{Cl})$ & $5-14$ yrs $(95 \% \mathrm{Cl})$ & $15-49$ yrs $(95 \% \mathrm{Cl})$ & $50-64$ yrs $(95 \% \mathrm{Cl})$ & $65+(95 \% \mathrm{Cl})$ \\
\hline HIV-related & $27.1(18.5-35.7)$ & $3.8(1.6-6.0)$ & $66.9(62.4-72.1)$ & $111.7(89.1-134.3)$ & 70.5 (46.9-93.4) \\
\hline MPNC & $4.4(0.5-7.6)$ & - & $1.0(0.1-1.8)$ & - & $0.3(0.0-0.7)$ \\
\hline Injuries & $2.8(0.0-5.1)$ & $4.2(1.9-6.4)$ & $18.7(14.7-22.4)$ & $14.7(2.1-24.6)$ & $27.7(10.8-41.2)$ \\
\hline Lifestyle & $0.7(0.0-1.5)$ & $0.9(0.0-1.9)$ & $5.3(3.4-7.1)$ & $96.7(77.8-116.4)$ & $295.6(260.9-333.1)$ \\
\hline Other NCD & - & $1.1(0.0-2.1)$ & $1.6(0.6-2.5)$ & $19.8(6.3-30.2)$ & $19.7(6.8-31.1)$ \\
\hline Other CD & $51.2(42.8-60.0)$ & $1.7(0.2-3.0)$ & $1.0(0.1-1.8)$ & 7.5 (0.0-13.6) & $14.5(4.9-23.1)$ \\
\hline Indeterminate & $25.8(19.4-31.5)$ & $4.8(2.8-6.5)$ & $20.5(17.5-23.3)$ & $60.3(44.7-74.0)$ & $173.6(145.9-197.4)$ \\
\hline 2009 & $0-4$ yrs $(95 \% \mathrm{Cl})$ & $5-14$ yrs $(95 \% \mathrm{Cl})$ & $15-49$ yrs $(95 \% \mathrm{Cl})$ & $50-64$ yrs $(95 \% \mathrm{Cl})$ & $65+(95 \% \mathrm{Cl})$ \\
\hline HIV-related & $11.7(6.2-16.7)$ & $5.6(3.6-7.7)$ & $58.3(53.9-62.3)$ & $114.9(94.5-137.2)$ & $78.3(51.7-103.4)$ \\
\hline MPNC & $0.9(0.0-2.1)$ & - & $1.2(0.2-2.1)$ & - & $3.1(0.0-6.2)$ \\
\hline Injuries & $3.0(0.0-5.7)$ & $1.5(0.0-2.9)$ & $15.4(11.7-18.9)$ & $12.3(1.6-20.9)$ & $15.7(2.6-27.0)$ \\
\hline Lifestyle & $0.4(0.0-0.9)$ & $0.1(0.0-0.2)$ & $5.3(3.3-7.0)$ & 94.5 (74.9-113.8) & $285.8(249.9-322.0)$ \\
\hline Other NCD & - & - & $1.5(0.4-2.3)$ & $20.6(8.4-30.6)$ & $29.2(14.4-42.9)$ \\
\hline Other CD & $45.2(38.2-52.2)$ & $0.8(0.0-1.5)$ & $1.1(0.2-1.8)$ & $6.2(0.3-11.0)$ & $9.6(0.9-16.9)$ \\
\hline Indeterminate & $36.1(29.0-44.0)$ & $2.3(1.0-3.5)$ & $26.9(23.7-30.1)$ & $89.4(70.0-106.1)$ & $185.6(157.9-212.9)$ \\
\hline
\end{tabular}

Noncommunicable-disease mortality increased with increasing age and was the major cause of death in the 65 -and-older age group. There were no clear trends in noncommunicable disease mortality over time.

The proportions of indeterminate causes in this study for the different age groups were generally lower than the levels reported by Byass [20] for the Agincourt site, with the exception of the under- 5 age group. In the under-5 age group, $32 \%$ in this study compared to $26 \%$ in the Byass study; $21 \%$ in this study compared to $38 \%$ in the Byass study in the 5-14 age group; $12 \%$ in this study compared to $26 \%$ in the Byass study in the $15-49$ age group; $17 \%$ in this study compared to $31 \%$ in the Byass study in the 50-64 age group, and $25 \%$ in this study compared to $33 \%$ in the Byass study in the $65-$ and-older age group.
The verbal autopsy questionnaire was not designed from inception with the InterVA input indicators in mind. A number (18 out of 106 indicators) did not map directly to the questionnaire and had to be derived indirectly. Data quality in relation to the InterVA input indicators could not be monitored on an ongoing basis and some of the changes over time in the indeterminate-cause proportion could reflect data-quality issues.

\section{Conclusions}

There has been a substantial decline in proportion of deaths due to HIV-related causes in the under-5 age group over the study period coupled with a fairly constant mortality rate due to other communicable diseases and indeterminate causes. This would indicate that further gains in reducing under-5 mortality would 


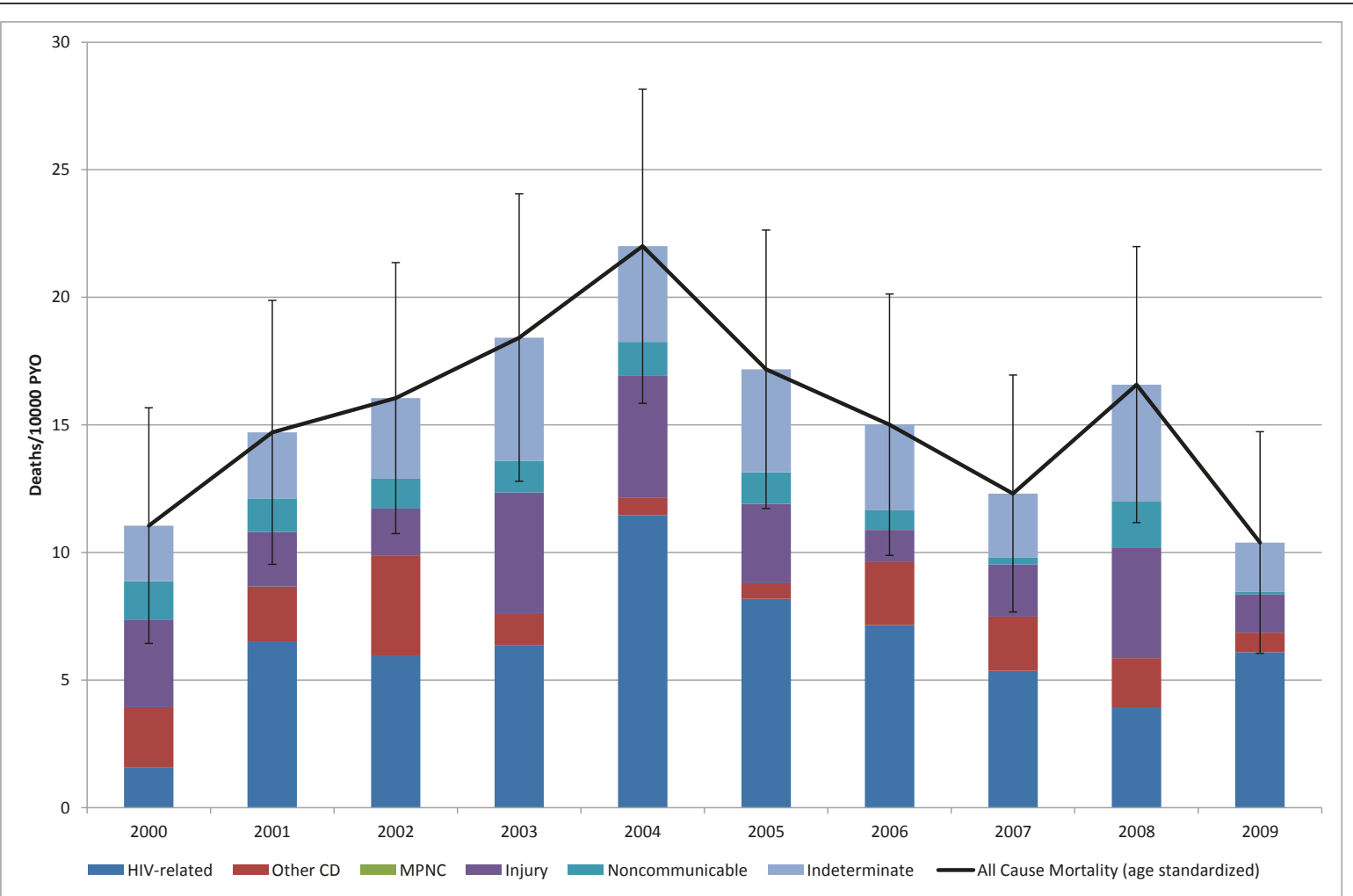

Figure 4 5-14 yr Age Standardized Mortality. (Deaths 333, Person Years Observed (PYO) 216, 005).

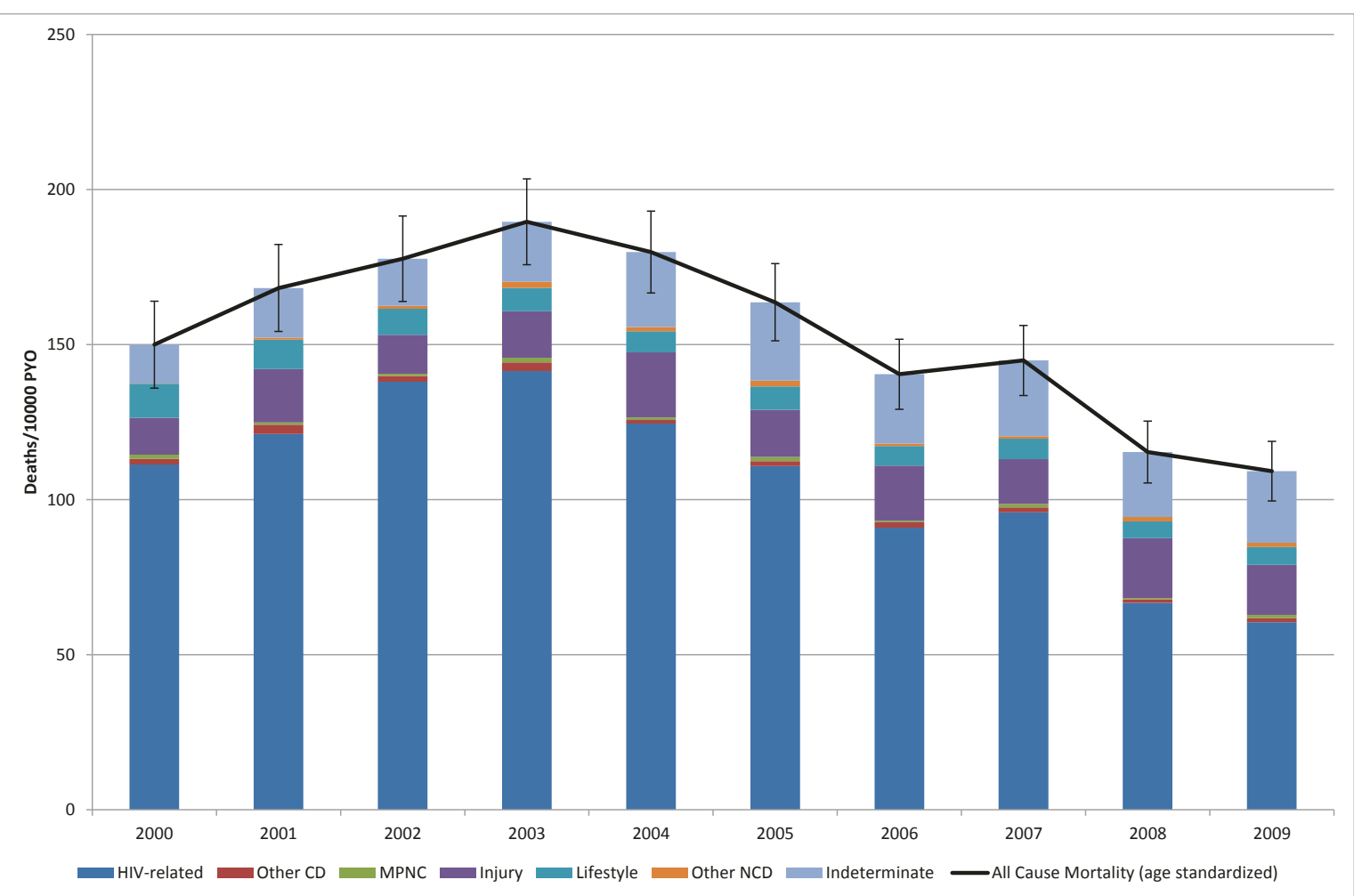

Figure 5 15-49 yr Age Standardized Mortality. (Deaths 5, 863, Person Years Observed (PYO) 387, 630). 


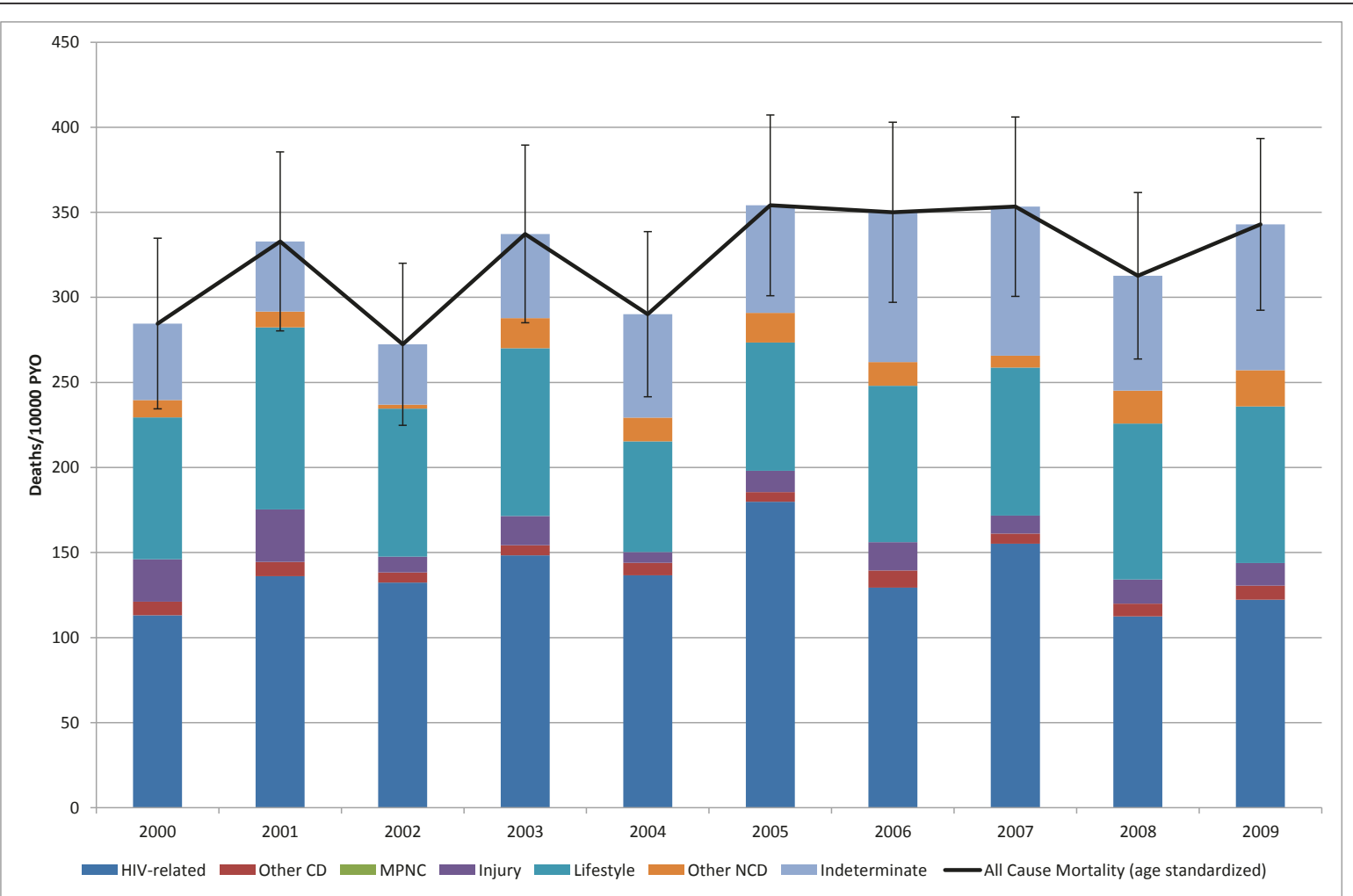

Figure 6 50-64 yr Age Standardized Mortality. (Deaths 1, 526, Person Years Observed (PYO) 47, 118).

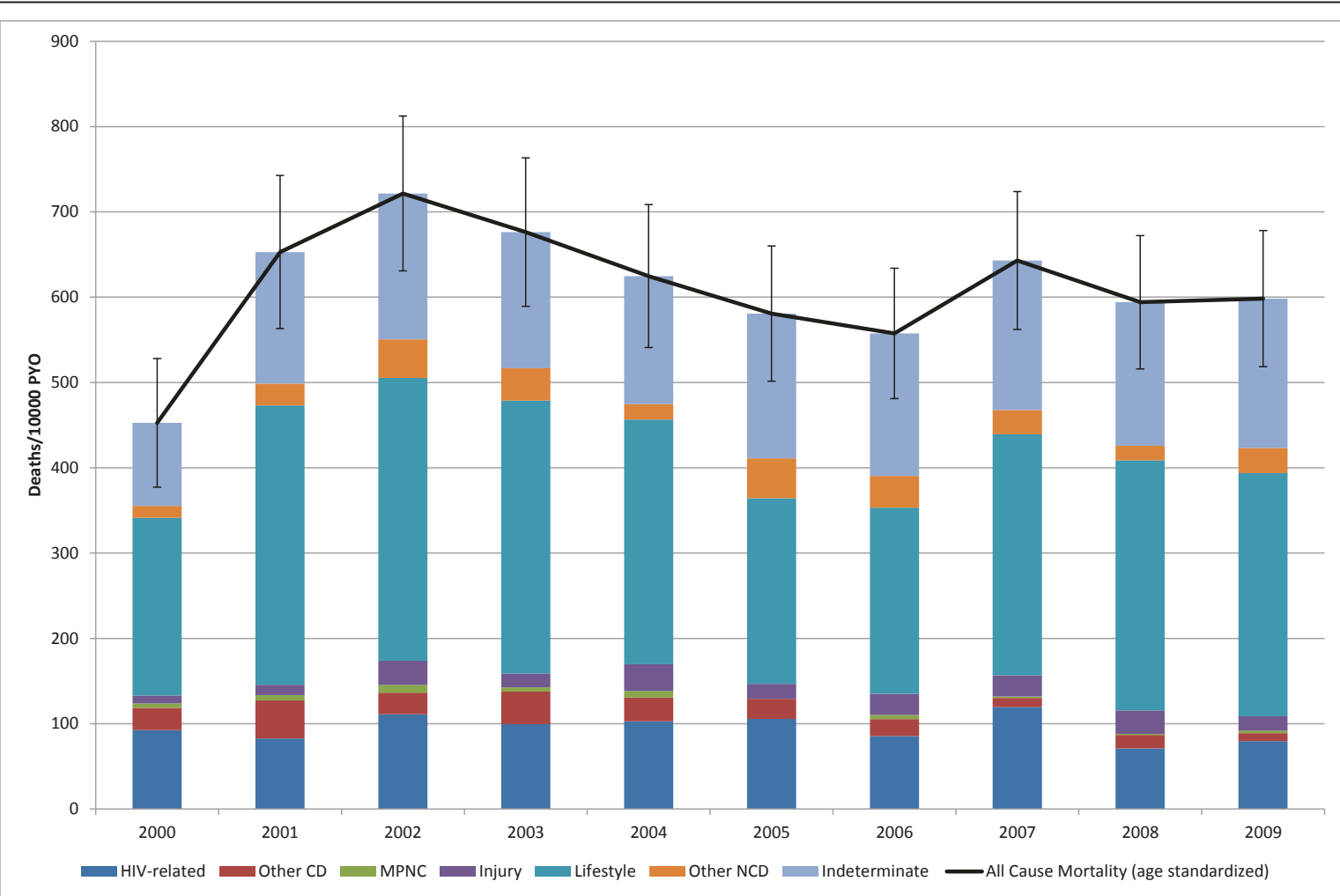

Figure 7 65+yr Age Standardized Mortality. (Deaths 1, 526, Person Years Observed (PYO) 47, 118). 
Table 4 Agreement between physician and InterVA cause of death allocation by age group

\begin{tabular}{cccc}
\hline Age Group & Agreement & $\begin{array}{c}\text { Kappa } \\
\text { (95\% confidence interval) }\end{array}$ & $\mathbf{p}$ \\
\hline $0-4$ & $61 \%$ & $0.43(0.40-0.46)$ & $<0.0001$ \\
$5-14$ & $76 \%$ & $0.68(0.63-0.74)$ & $<0.0001$ \\
$15-49$ & $86 \%$ & $0.71(0.70-0.72)$ & $<0.0001$ \\
$50-64$ & $77 \%$ & $0.68(0.65-0.70)$ & $<0.0001$ \\
$65+$ & $68 \%$ & $0.50(0.48-0.53)$ & $<0.0001$ \\
\hline Overall & $79 \%$ & $0.68(0.67-0.69)$ & $<0.0001$ \\
\hline
\end{tabular}

require investigation of causes other than HIV and possibly changes in public health services. Further research is required to determine whether the resilience to change in other communicable disease mortality is due to interaction between interventions aimed at HIV and those aimed at other causes of child mortality, or due to unrelated factors.

In the 15-49 age group, the positive impact of HIVrelated interventions was substantial. We did not explore sex-specific mortality, but given the different age pattern in HIV prevalence [27], one would expect some differences in the sex-specific HIV-related mortality trends. Although trauma mortality is dwarfed by HIV-related mortality in this age group, it is still considerably higher than the global mortality estimate [38].

In the older age groups, the dual burdens of communicable and noncommunicable diseases were evident. The lack of a substantial decline in HIV-related mortality in those over 50 years old requires further investigation to determine whether this was due to lack of access or response to treatment programs or an artifact of competing risks from other mortality causes.

The InterVA verbal autopsy program performed well, and the conclusions based on InterVA mortality cause allocation would have been no different had they been based on physician mortality cause allocation. The InterVA program allowed more timely analysis of causespecific mortality; as a result we could include the 2009

Table 5 Agreement between physician and InterVA cause of death allocation by year

\begin{tabular}{cccc}
\hline Year & Agreement & $\begin{array}{c}\text { Kappa } \\
\text { (95\% confidence interval) }\end{array}$ & $\mathbf{p}$ \\
\hline 2000 & $78 \%$ & $0.67(0.64-0.70)$ & $<0.0001$ \\
2001 & $82 \%$ & $0.72(0.69-0.74)$ & $<0.0001$ \\
2002 & $82 \%$ & $0.71(0.68-0.74)$ & $<0.0001$ \\
2003 & $78 \%$ & $0.66(0.63-0.69)$ & $<0.0001$ \\
2004 & $77 \%$ & $0.66(0.63-0.69)$ & $<0.0001$ \\
2005 & $75 \%$ & $0.63(0.61-0.66)$ & $<0.0001$ \\
2006 & $76 \%$ & $0.66(0.63-0.69)$ & $<0.0001$ \\
2007 & $79 \%$ & $0.69(0.66-0.72)$ & $<0.0001$ \\
2008 & $79 \%$ & $0.72(0.69-0.75)$ & $<0.0001$ \\
\hline
\end{tabular}

deaths in this analysis in spite of the fact that physician coding is not yet complete for 2009 .

Verbal autopsy based methods enabled the timely measurement of changing trends in cause-specific mortality to provide policymakers with the much-needed information to allocate resources to appropriate health interventions.

\section{Acknowledgements}

We thank the community members in the demographic surveillance area who have contributed their data to the study since 2000. We appreciate the contribution of the research operations staff of the Africa Centre in collecting the data used in this paper. Erofili Grapsa assisted with the statistical analysis. Nuala McGrath and Till Bärnighausen provided statistical advice. Peter Byass and Ed Fottrell provided assistance with implementing InterVA. The demographic surveillance is funded by the Wellcome Trust. The verbal autopsy program was partially funded by the MTN Foundation.

\section{Author details}

${ }^{1}$ Africa Centre for Health and Population Studies, University of KwaZuluNatal, Somkhele, South Africa. ${ }^{2}$ MRC Centre of Epidemiology for Child Health, UCL ICH, London, UK.

\section{Authors' contributions}

AJH was responsible for the data analysis and drafting the manuscript. TM supervised the verbal autopsy data collection and participated in the data analysis. MLN is the director of the Africa Centre and contributed to the drafting and reviewing of the manuscript. All authors have read and approved the final manuscript.

\section{Competing interests}

The authors declare that they have no competing interests.

Received: 12 February 2011 Accepted: 5 August 2011

Published: 5 August 2011

\section{References}

1. Rajaratnam JK, Marcus JR, Levin-Rector A, Chalupka AN, Wang H, Dwyer L, Costa M, Lopez AD, Murray CJ: Worldwide mortality in men and women aged 15-59 years from 1970 to 2010: a systematic analysis. Lancet 2010, 375:1704-1720.

2. Black RE, Cousens S, Johnson HL, Lawn JE, Rudan I, Bassani DG, Jha P, Campbell H, Walker CF, Cibulskis R: Global, regional, and national causes of child mortality in 2008: a systematic analysis. The Lancet 2010.

3. Stanecki K, Daher J, Stover J, Akwara P, Mahy M: Under-5 mortality due to HIV: regional levels and 1990-2009 trends. Sexually Transmitted Infections 2010, 86:ii56.

4. Bradshaw D, Laubscher R, Dorrington R, Bourne DE, Timaeus IM: Unabated rise in number of adult deaths in South Africa. South African Medical Journal 2008, 94:278.

5. Statistics South Africa: Mortality and causes of death in South Africa, 2008: Findings from death notification Pretoria; 2010.

6. Chopra M, Daviaud E, Pattinson R, Fonn S, Lawn JE: Saving the lives of South Africa's mothers, babies, and children: can the health system deliver? The Lancet 2009, 374:835-846.

7. Herbst A, Cooke G, Bärnighausen T, KanyKany A, Tanser F, Newell M: Adult mortality and antiretroviral treatment roll-out in rural KwaZulu-Natal, South Africa. Bull World Health Organ 2009, 87:754-762.

8. Ndirangu J, Newell M, Tanser F, Herbst A, Bland R: Decline in early life mortality in a high HIV prevalence rural area of South Africa: evidence of HIV prevention or treatment impact? AIDS 2010, 24:593-602.

9. Floyd S, Molesworth A, Dube A, Banda E, Jahn A, Mwafulirwa C, Ngwira B, Branson K, Crampin AC, Zaba B, et al: Population-level reduction in adult mortality after extension of free anti-retroviral therapy provision into rural areas in northern Malawi. PLoS One 2010, 5:e13499.

10. Bendavid E, Bhattacharya J: The President's Emergency Plan for AIDS Relief in Africa: an evaluation of outcomes. Annals of internal medicine 2009, 150:688 
11. Reniers G, Araya T, Davey G, Nagelkerke N, Berhane Y, Coutinho R, Sanders EJ: Steep declines in population-level AIDS mortality following the introduction of antiretroviral therapy in Addis Ababa, Ethiopia. AIDS (London, England) 2009, 23:511.

12. Gregson S, Gonese E, Hallett TB, Taruberekera N, Hargrove JW, Lopman B, Corbett EL, Dorrington R, Dube S, Dehne K: HIV decline in Zimbabwe due to reductions in risky sex? Evidence from a comprehensive epidemiological review. International Journal of Epidemiology 2010, 1-13.

13. Mayosi BM, Flisher AJ, Lalloo UG, Sitas F, Tollman SM, Bradshaw D: The burden of non-communicable diseases in South Africa. The Lancet 2009, 374:934-947.

14. Seedat M, Van Niekerk A, Jewkes R, Suffla S, Ratele K: Health in South Africa 5-violence and injuries in South Africa: prioritising an agenda for prevention. Lancet 2009, 374:1011-1022.

15. Fottrell E: Dying to count: mortality surveillance in resource-poor settings. Glob Health Action 2009, 2.

16. Sankoh $\mathrm{O}$ : Global health estimates: stronger collaboration needed with low- and middle-income countries. PLoS Med 2010, 7:e1001005.

17. Nojilana B, Groenewald P, Bradshaw D, Reagon G: Quality of cause of death certification at an academic hospital in Cape Town, South Africa. S Afr Med J 2009, 99:648-652.

18. Yudkin PL, Burger EH, Bradshaw D, Groenewald P, Ward AM, Volmink J: Deaths caused by HIV disease under-reported in South Africa. AIDS 2009, 23:1600-1602.

19. Hosegood V, Vanneste AM, Timaeus IM: Levels and causes of adult mortality in rural South Africa: the impact of AIDS. AIDS 2004, 18:663-671.

20. Byass $P$, Kahn $K$, Fottrell E, Collinson MA, Tollman SM: Moving from data on deaths to public health policy in Agincourt, South Africa: approaches to analysing and understanding verbal autopsy findings. PLoS Med 2010, 7:e1000325.

21. Cook I, Alberts M, Burger S, Byass P: All-cause mortality trends in Dikgale, rural South Africa, 1996-2003. Scandinavian journal of public health 2008, 36:753.

22. Fottrell E, Byass P: Verbal autopsy: methods in transition. Epidemiol Rev 2010, 32:38-55.

23. Soleman N, Chandramohan D, Shibuya K: Verbal autopsy: current practices and challenges. Bull World Health Organ 2006, 84:239-245.

24. King G, Lu Y, Shibuya K: Designing verbal autopsy studies. Popul Health Metr 2010, 8:19.

25. Byass P, Fottrell E, Dao LH, Berhane Y, Corrah T, Kahn K, Muhe L, Do DV: Refining a probabilistic model for interpreting verbal autopsy data. Scand J Public Health 2006, 34:26-31.

26. Tanser F, Hosegood V, Bärnighausen T, Herbst K, Nyirenda M, Muhwava W, Newell C, Viljoen J, Mutevedzi T, Newell M: Cohort Profile: Africa Centre Demographic Information System (ACDIS) and population-based HIV survey. Int J Epidemiol 2008, 37:956-962.

27. Welz T, Hosegood V, Jaffar S, Bätzing-Feigenbaum J, Herbst K, Newell M: Continued very high prevalence of HIV infection in rural KwaZulu-Natal, South Africa: a population-based longitudinal study. AIDS 2007, 21:1467-1472.

28. Bärnighausen T, Tanser F, Gqwede Z, Mbizana C, Herbst K, Newell M: High HIV incidence in a community with high HIV prevalence in rural South Africa: findings from a prospective population-based study. AIDS 2008, 22:139-144.

29. Bärnighausen T, Welz T, Hosegood V, Bätzing-Feigenbaum J, Tanser F, Herbst K, Hill C, Newell M: Hiding in the shadows of the HIV epidemic: obesity and hypertension in a rural population with very high HIV prevalence in South Africa. J Hum Hypertens 2008, 22:236-239.

30. Garrib A, Herbst AJ, Hosegood V, Newell ML: Injury mortality in rural South Africa 2000 - 2007: rates and associated factors. Tropical Medicine \& International Health 2011, 16:439-446.

31. INDEPTH Standardized Verbal Autopsy questionnaire (Revised August 2003). [http://www.indepth-network.org/index.php? option=com_content\&task=view\&id=96\&ltemid=184]

32. Baiden F, Bawah A, Biai S, Binka F, Boerma T, Byass P, Chandramohan D, Chatterji S, Engmann C, Greet D, et al: Setting international standards for verbal autopsy. Bulletin of the World Health Organization 2007, 85:570-571.

33. World Health Organization: International statistical classification of diseases and related health problems, 10th revision Switzerland, Geneva: WHO Library; 1992.
34. Lopez AD, Mathers CD, Ezzati M, Jamison DT, Murray CJL, (Eds.): Global Burden of Disease and Risk Factors Washington: Oxford University Press and The World Bank; 2006.

35. Ulm K: A simple method to calculate the confidence interval of a standardized mortality ratio (SMR). American journal of epidemiology 1990, 131:373-375.

36. R Development Core Team: $R$ : A language and environment for statitical computing Vienna: R Foundation for Statistical Computing; 2010.

37. STATACorp: Statistical Software Release 11.0 College Station, TX: Stata Corporation; 2010.

38. Peden M, McGee K, Sharma G: The injury chart book: a graphical overview of the global burden of injuries. Book The injury chart book: a graphical overview of the global burden of injuries City: World Health Organisation; 2002.

doi:10.1186/1478-7954-9-47

Cite this article as: Herbst et al:: Verbal autopsy-based cause-specific mortality trends in rural KwaZulu-Natal, South Africa, 2000-2009. Population Health Metrics 2011 9:47.

\section{Submit your next manuscript to BioMed Central and take full advantage of:}

- Convenient online submission

- Thorough peer review

- No space constraints or color figure charges

- Immediate publication on acceptance

- Inclusion in PubMed, CAS, Scopus and Google Scholar

- Research which is freely available for redistribution

Submit your manuscript at www.biomedcentral.com/submit
Biomed Central 